\title{
BIOLOGICALLY INFORMED DISCIPLINES: A COMPARATIVE ANALYSIS OF BIONICS, BIOMIMETICS, BIOMIMICRY, AND BIO-INSPIRATION AMONG OTHERS
}

\author{
A. IOUGUINA ${ }^{1}$, J.W. DAWSON ${ }^{2}$, B. HALLGRIMSSON ${ }^{1} \&$ G. SMART ${ }^{3}$ \\ ${ }^{1}$ School of Industrial Design, Carleton University, Canada \\ ${ }^{2}$ Department of Biology, Carleton University, Canada \\ ${ }^{3}$ School of Linguistics and Language Studies, Carleton University, Canada
}

\begin{abstract}
This article offers a complementary approach to research and education in biologically informed disciplines through the lens of bionics, biomimetics, and biomimicry terminology. For the purpose of developing this approach, we look at past and current contexts in which the three fields have emerged and identify three issues: an absence of common ground that unites the fields of bionics, biomimetics, and biomimicry while recognizing their contextual differences, a non-standardized use of the terminology that leads to ambiguity within the field of biologically informed disciplines, an incomplete and disorganized historical and contextual knowledge about the field that inhibits a common starting ground for collaboration, and confuses non-scientists who seek biological understanding. We offer a fundamental understanding of the fields from theoretical perspective by bringing together opinions of researchers and practitioners of bionics, biomimetics, biomimicry, bio-inspiration and offering a comprehensive analysis of terms culminating in the introduction of an overarching term 'biologically informed disciplines'.

Keywords: bio-inspiration, biologically informed disciplines, biomimetics, biomimicry, bionics, linguistic discourse.
\end{abstract}

\section{HISTORICAL DEVELOPMENTS}

It took half a century and the occurrence of scientifically, technologically, and socially important events before a separate field that can be described as collaboration between natural sciences and applied sciences and arts began to be widely recognized outside of highly specialized expert communities. This paper is devoted to an analysis of development of the three events in order to set the stage for the contextual analysis of the fields that continue to enjoy fruitful interdisciplinary collaboration - the most prominent of which are bionics [1], biomimetics [2], and biomimicry [3].

\subsection{Bionics and self-replication of living and non-living matter}

At a time when cybernetics, defined by Norbert Wiener as 'the scientific study of control and communication in the animal and the machine' [4], was a burgeoning field, Heinz Von Foerster, Professor of Electrical Engineering at the University of Illinois at Urbana-Champaign, greatly contributed to the field by establishing the Biological Computer Laboratory (BCL) in 1958. The focus of the research at the BCL was on systems theory, and generated many challenging questions that gave rise to the new field of bionics. Some of the research questions included: How can a machine replicate itself? How can machines regenerate lost parts, as many kinds of organisms are able to do? [27]

The term bionics, combined from the words biology and technics, was conceived by Jack Steele of the US Air Force Medical Division in 1960 [5]. Jack Ellwood Steele (1924-2009) studied General Engineering at the University of Illinois and the Illinois Institute of Technology before earning his medical degree from Northwestern University Medical School in 1950. According to Butsch and Oestreicher (1963), bionics aims to translate the information processing capability of living systems 
into design challenges. During the highly active times of the BCL, bionics served as a general catchword that covered attempts to analyze biological processes and to implement them using computers. Dr. Jack Steele, a prominent engineer and psychiatrist with emphasis on neuroanatomy, went on to co-organize the first Bionics Symposium, held at the Wright-Patterson Air Force Base in Ohio in 1960 [6].

As the decades advanced, bionics matured into a well-defined field in Europe [7], while largely disappearing from North America. A German biologist Werner Nachtigall independently founded the field in 1960s and, along with Carmelo di Bartolo, Jurgen Hennicke and Gabriel Songel, formulated a set of principles that would guide bionics practitioners in their collaborative process [8]. Daniel Wahl, a founder of Sustainability Consultancy Innovation Education, mentioned in his paper 'Bionics vs. Biomimicry: from control of nature to sustainable participation in nature' that 'Germany is currently taking a leading role in the field of bionics research' [7] establishing the 'Society for Technical Biology and Bionics' and the 'Bionics Competency Network'. Wahl took a radically different approach to the evaluation of the term bionics, describing it from the perspective of 'natureculture relationships' and indicating the deficiency of 'salutogenic design approach that increases human, societal, and ecological health synergistically' [7].

\subsection{Biomimetics and the interface between physical and biological sciences}

Otto Herbert Schmitt, an American biophysicist and one of the key founders of the biomedical engineering field [9], officially coined the term biomimetics, a derivative of Greek words bios (life) and mimesis (imitate) [5], in his publication 'Some Interesting and Useful Biomimetic Transforms', which he presented at the Proceedings of Third International Biophysics Congress in Boston, Massachusetts [2]. More than three decades earlier, Schmitt developed a physical device that mimicked the electrical action of a nerve as part of his doctoral research [10], illustrating a similar trait to that of bionics: practice precedes theory. Schmitt (1913-1998) was a graduate of Washington University in the United States and of the University College London in England with degrees in zoology, physics, mathematics, and a post-doctorate degree in biophysics. Such an early emphasis on the interface between biological and physical sciences expanded and deepened through Schmitt's career as Professor of Biophysics, Bioengineering, and Electrical Engineering at the University of Minnesota. A list of biomimetics applications has grown significantly since Schmitt's study of the neural impulse propagation in squid nerves and subsequent invention of the Schmitt trigger in 1934.

According to Bar-Cohen, '[biomimetics] represents study and imitation of nature's methods, designs, and processes' [5]. Julian Vincent of the Centre for Biomimetic and Natural Technologies at the University of Bath, UK, published a paper titled 'Biomimetics: its practice and theory' (2006), in which he asserted that biomimetics is the original representation of 'a relatively young study embracing the practical use of mechanisms and functions of biological science in engineering, design, chemistry, electronics, and so on' [11] and indicated that 'people are inventing an increasing number of other words to label the area, thus giving them some sort of exclusivity' [12]. Unlike the general principles of biomimicry and bionics, the principles of biomimetics are based on nature's mechanical capabilities and are rooted in specific examples from nature [13].

Decades prior to Bar-Cohen's formulation of biomimetic principles, Otto Schmitt labored to unite biological and physical sciences using the lens of an engineer, while stating one major shortcoming of this collaboration: 'Biophysics is a biologist's approach to problems of physical science and engineering, although this aspect has largely been neglected' [14]. In his view, the communities of bionics and biomimetics were still dominated by engineers and physicists with little regard for biological sciences. However, the scale was tipped with the arrival of the living systems theory. 


\subsection{Biomimicry as a result of living systems theory and holistic thinking}

Living systems theory, of course, is not new. It is the domain of biology, ecology, and any other discipline that incorporates systems thinking into its research and practice. McCulloch began the discussion during the Second Annual Bionics Symposium: 'the structures which evolve are suited to the world in which they evolve' [1], followed by published works of systems scientists Ervin Laszlo and Erich Jantsch, physicist Fritjof Capra, and biologist James G. Miller, among many others [1518]. Furthermore, Dr. Adrian Bejan of Duke University introduced the Constructal law in 1996, which expanded laws of thermodynamics beyond physics to encompass design, engineering, economics, politics, and other applied disciplines [19]. Dr. Bejan states, 'Constructal law runs against reductionism, and empowers the mind to see the whole, its design, performance, and future' to ultimately 'rationalize macroscopic design, objective, and behaviour' [20].

According to Daniel Wahl, an expert in Natural Design and Whole Systems Design, 'during the 1970s, research at the 'New Alchemy Institute' began to explore how ecology, biology, and a biocybernetics system approach, could inform more sustainable solutions to meeting fundamental human needs' [7]. This research culminated in nine precepts of biological design and reflected holistic, living systems focused approach [21], which spread worldwide during 1980s, 1990s, and 2000s. The diverse movements sprouted and took forms of 'biomimicry, ecological design, cradle-to-cradle design, industrial ecology, biophilic design, whole systems design, scale-linking design, bioregional design, and salutogenic design' [22].

Janine Benyus (1958) is a graduate of Rutgers University with degrees in natural resource management and English literature and writing, is a natural sciences writer, innovation consultant, and author of six books, including Biomimicry: Innovation Inspired by Nature [3]. According to Benyus, the term biomimicry can be defined using three parameters of Nature: model, measure, and mentor. Thus, biomimicry does not just imitate or take inspiration from nature but also uses an ecological standard to judge the appropriateness of an innovation and 'introduces an era based not on what we can extract from the natural world, but on what we can learn from it' [3]. The youngest of the fields, biomimicry speculatively takes inspiration from natural design proposed by John Todd and his wife Nancy Jack-Todd in the 1970s [21,23], which 'offered a list of [nine] principles for ecologically or biologically informed design' 'augmented by a tenth precept that was added more recently' [7]. Fritjof Capra - a prominent physicist and founder of Center for Ecoliteracy later expanded on the list - these principles of ecology transformed into 'the language of Nature' (1994) and caused a perceptual shift in 'the link between ecological and human communities' [24]. Founders of The Biomimicry 3.8 Institute identify a successful mimicry of nature through emulation of natural forms, processes, and systems as well as through trademarked Ethos, Emulate, (Re)Connect approach [25]. The Emulate component may be equally applied to definitions of the terms bionics, biomimetics, biomimicry, yet it is the Ethos and $(\mathrm{Re})$ Connect components that set biomimicry apart and allow for greater public accessibility, while diverting the focus of those in the field from technical complexity. Today, biomimicry spans various fields of human systems: from reimaging the way, we feed ourselves to how we conduct business and make things [3] with great emphasis on sustainability, promoted by The Biomimicry 3.8 Institute.

\subsection{Summary of historical developments}

The analysis of history surrounding the terms bionics, biomimetics, and biomimicry partially covers the scope of the overarching question: 'How do experts, that founded and actively participated in the fields of bionics, biomimetics, and biomimicry as they evolved, perceive and define the fields?' 
It became evident from research that the meanings of terms depend on a whole set of interconnected notions, including educational and professional backgrounds of the founders; Jack Steele received a medical degree and worked in the US Air Force Medical Division, Otto Schmitt earned a degree in biophysics and worked as a Professor of Bioengineering at the University of Minnesota as well as at Wright-Patterson Air Force Base in Dayton with Jack Steele, and Janine Benyus earned a degree in natural resource management and English literature and writing, eventually co-founding The Biomimicry 3.8 Institute in Montana. Many theoretical advances of the early 20th century in physical sciences led to applications of their theories and technologies for studying biological sciences that gave rise to the fields of bionics and biomimetics. As the biological sciences advanced during the 20th century, the fields of bionics and biomimetics evolved almost simultaneously to tackle the complex subsystems of cells (neurons), tissues (muscles), organs (heart, brain, etc.), and organ systems (nervous system, cardiovascular system, etc.). Although it was understood on a conceptual level that the organizational levels are tightly interlocked (as evident from quotes by Otto Schmitt and principles of bionics), most researchers focused on a single system in great detail (for example, nervous system in the case of bionics and biomimetics).

As time progressed, however, biologists began gaining the capability to go beyond the interactions of components within a single system [26]. As the fields of bionics, biomimetics, and biomimicry are now developing almost in parallel, the sheer volume of knowledge generated in each of these fields makes it increasingly difficult for researchers who study a nervous system (such as experts in the field of bionics) to keep up with the progress being made by researchers studying ecosystems (such as experts in the field of biomimicry).

It is time to highlight the connections between the fields of bionics, biomimetics, and biomimicry. This will hopefully provide an opportunity for experts to combine their different skills and perspectives and to accelerate the development of theoretical and practical approaches in biologically informed disciplines. However, discovering and understanding the features that make these fields unique and similar will bring about a productive acceleration to the development of bionics, biomimetics, and biomimicry.

\section{THE FIELDS OF BIONICS, BIOMIMETICS, AND BIOMIMICRY AS SEEN BY THE EXPERTS TODAY}

An online survey of experts was conducted to find out more about the current cultural context of the fields and learn diverse perspectives of the leading experts that research and practice bionics, biomimetics, and biomimicry today.

The results from the survey included 25 respondents, who identified themselves to be biologists, physicists, designers, architects, and engineers working in the fields of bionics, bio-inspiration, biomimetics, and bio-inspired engineering, with the majority of respondents identifying themselves with the field of biomimicry with varied levels of experience.

\subsection{Variations of the term 'mimicry' within biology and design}

The first question was 'How do you interpret the term mimicry within the fields of biology and design?'

Biologists identified an encyclopedic meaning of mimicry as an imitation of an external appearance, shape, and behavior of a model to enhance survival. For designers, engineers, and architects, mimicry surpassed encyclopedic definition and gained a new meaning of 'understanding', 'discovering', and 'abstracting' for the purpose of 'innovative', 'sustainable' designs that surpass form and focus on function, process, and system. As a result, biologists and designers that choose to collaborate 
on a project may face obstacles in their communication due to the misalignment of these definitions. The biologist may view the goal of a project as an imitation of a form found in nature, while a designer may be more interested in understanding and translating the principles behind the function. Thus, practitioners of biomimicry and biomimetics could benefit from awareness of this misnomer and make their intentions clear in the beginning of the project.

\subsection{Bionics $\neq$ biomimetics $\neq$ biomimicry}

The experts were then asked to give their personal opinions on the comparative equability of the terms bionics, biomimetics, and biomimicry. The three questions aimed at revealing how the experts evaluated terminology, and in particular, how the role of each term was seen compared with the others. First, we asked the following question: 'In your professional opinion, does biomimicry = biomimetics = bionics? Why or why not?' The responses indicated that none of the participants thought that biomimicry was equal to bionics. However, 8 experts responded that bionics matched the meaning of biomimetics, and 11 experts responded that biomimetics was identical to biomimicry.

We then posed a statement 'Making a clear distinction between the meanings of the above terms is, or could be, very useful' prompting the experts to reflect on the relevance of the study. Aside from a clear need for an organized terminology in the field of biologically informed disciplines - the majority of respondents either agreed $(44 \%)$ or strongly agreed $(32 \%)$ with the statement - the responses illustrated some of the different components that comprise the terms in question.

\subsubsection{Bionics}

Experts position bionics within disciplines of biology and engineering, more specifically the industries of 'robotics', 'mechanics' and 'medicine'. Bionics employs 'physics principles' with the end-goal of creating 'innovative' 'functional products' with no regard for 'ecology'.

The first four components categorize bionics into an amalgam of biology and engineering disciplines, conceptualized primarily as a sub-field of engineering, focused primarily in robotics and mechanics. The 'purpose' component centers on the final outcome of innovative functional products that may incorporate synthetic design with organic matter. It is interesting to notice that the 'context' component is defined in relation to sustainability or ecology. This kind of focus is an evidence of bias among respondents, the majority of whom relate themselves to the field of biomimicry (52\%).

\subsubsection{Biomimicry}

Experts position biomimicry mainly within the disciplines of design, business, architecture, and a general field of philosophy with a broad subject field that allows for a greater accessibility to a general public, whose main interest is 'form, process, systems' design, nature-focused ethos, and environmental sustainability.

Responses detail that although mostly focused in the field of design, biomimicry carries much broader interpretations and presents less technical complexity than bionics, rendering it a general philosophical approach to 'how people fit into the natural world'. Many references to the connection between sustainability and human-nature connection leads to a conclusion that this is the main public declaration of intentions by The Biomimicry 3.8 Institute. Some of the evidence in support of the above components comes in the form of phrases such as: 'Learns from nature, connects with nature', 'Holistic view that generates innovation to be more like nature in sustaining and generative way'.

In further support of a nature-focused ethos, a member of the Biomimicry Institute asserts in the survey: 'It differs in that it incorporates Ethos, Emulate, and (Re)Connect with nature, what we at 
Biomimicry 3.8 are calling the Essential Elements. The Ethos piece is about seeking sustainable designs, [...]. The Emulate piece is about learning from the organism or system how it meets its challenge or function, then applying the abstracted design principle to the design. (Re)Connect means remembering that we humans are part of nature, not separate from it.' The Emulate component may be equally applied to definitions of all three terms, yet it is the Ethos and (Re)Connect components that set biomimicry apart and allow for greater public accessibility, while diverting the focus of those in the field from technical complexity.

\subsubsection{Biomimetics}

Biomimetics is best described through comparative semantic analysis, because the majority of experts (76\% of respondents) equate the term to either bionics or biomimicry. In fact, eight experts think that biomimetics equals bionics. Thus, biomimetics can be defined as equal to bionics in its engineering focus lacking sustainability component and nature-focused ethos.

However, 11 experts think that biomimetic(s) is congruous with biomimicry. The first and most lexically interesting point is that four experts only view biomimetics as an adjective (biomimetic), the role of which is to describe the process or solutions with traits of biomimicry. In fact, one expert states: 'Unfortunately, there's no good adjective to go with biomimicry, so we often refer to biomimetic design when we refer to a design that meets our definition of biomimicry. I think that's part of the confusion for some.'

Moving on, it became evident that at least seven experts thought that the term biomimetics was congruent with biomimicry in its human-nature ethos and sustainability focus, while only one expert differentiated the term from the other two by positioning it exclusively in the discipline of material science.

In the analysis stated above for bionics, biomimicry, and biomimetics, the initial component includes 'innovation' and 'nature-inspired or mimicked or copied or learned' concepts, thereby establishing their position at a certain level of hierarchical ranking. What then are innovation and nature in the eyes of the experts as well as a variety of action verbs that attempt to describe the channeling of ideas from nature to innovation? Further research is needed to answer these questions.

\section{DISCUSSION}

The following postulations can be derived from the review of historical development and expert interviews:

\subsection{The fields of bionics and biomimicry differ in context and objective}

The online survey indicates that the main difference between the fields lies in their intent. The primary purpose of bionics is to promote creative problem solving and push innovation in the industries of robotics and mechanics by mainly employing physics principles, while the goal of biomimicry is to promote a firmly grounded sense of life sustaining principles through reconnection with nature in the fields of design, business, and architecture, by employing principles of biological sciences. Thus, it can be generalized that functional biologists and engineers primarily dominate the field of bionics, while the field of biomimicry is more welcoming of ecologists, environmental scientists, designers, architects, and economists. The fields of biomimetics and bio-inspiration were found to be the least concrete in their broad context and objective; however, they differentiate themselves by specializing in mechanical capabilities (in the case of biomimetics) and serving as an overarching term to describe the fields of bionics, biomimetics, and biomimicry (in the case of bio-inspiration). 


\subsection{Bionics, biomimetics and biomimicry differ in resulting solutions}

A biomimicry-driven project results in a solution firmly grounded in life sustaining principles yet lacks real-world applicability, while a bionics-driven project results in an applicable mechanically innovative solution that lacks in sustainability focus. As a result of these findings, we were able to conclude that the fields of bionics and biomimetics are primarily suitable for biologists, engineers, and designers interested in technical complexity of projects with a focus on technological innovation, whereas the field of biomimicry is more appropriate for biologists, designers, architects, economists, etc. driven by nature-focused ethos and seek minimal technical complexity.

\section{CONCLUSIONS AND FURTHER WORK}

\subsection{Biologically informed discipline as an overarching term}

Research was undertaken to try to find common ground that could unite the fields under the umbrella of one term. It is clear that all three fields are highly interdisciplinary in nature, yet they collaborate with one unifying discipline, namely biology. As a result of analyzing the definitions presented by experts, the following structure emerged:

Biologically Informed Discipline is: the informed interpretation of biological $[X]$ in order to address [Y] for the purpose of [Z].

The common denominator for $[\mathrm{X}]$ is 'knowledge' (hence the choice of 'informed' rather than 'inspired') and for [Y] is 'human challenges', thus formulating the definition for Biologically Informed Discipline as follows:

Biologically Informed Discipline is the informed interpretation of biological research in order to address human challenges for the purpose of innovation that may or may not result in sustainable solutions.

Thus, as evident from the definitions of bionics, biomimetics, and biomimicry, one structuring factor of Biologically Informed Discipline is the end goal of finding a solution. Depending on the context of the biologically informed field and the discipline within which biological knowledge is applied (industrial design, engineering, architecture, economics, etc.), different results are produced.

This paper contributes a study of terminology through extensive reading and listening. The findings obtained through primary research in combination with secondary research findings allow movement toward a general understanding of the differences and similarities that arise in the field. As designers begin to embrace and incorporate concepts and ideas from nature and biology, more extensive interaction between designers and biologists is inevitable. For effective interdisciplinary collaboration, a common understanding of certain terms is essential. Key elements of discourse that become integral and familiar to practitioners are shaped by both history and the culture of the various disciplines. Language evolves, it is plastic, fluid, and profoundly knowledge creating. Language can also be isolating and inhibitory when terms 'familiar' to different disciplines have acquired unique meaning.

Within the scope of collaboration between biologists and designers, we suggest the term biologically informed design having a potential utility, as an umbrella term, in interdisciplinary discourse. The term has a potential to embrace all the tenets of bionics, biomimetics, biomimicry, bio-inspiration, and others thereby incorporating additional value from these fields into the field of biologically informed disciplines. 


\section{REFERENCES}

[1] Bernard, E.E., Biological Prototypes and Synthetic Systems: Proceedings of the Second Annual Bionics Symposium, New York, 1962. doi: http://dx.doi.org/10.1007/978-1-4684-1716-6 7

[2] Schmitt, O.H., Some interesting and useful biomimetic transforms, Third International Biophysics Congress of the International Union for Pure and Applied Biophysics, Cambridge, 1969, p. 297.

[3] Benyus, J., Biomimicry: Innovation Inspired by Nature, Harper Collins: New York, 1997. doi: http://dx.doi.org/10.2307/4450504

[4] Wiener, N., Cybernetics, or Communication and Control in the Animal and the Machine, MIT Press: Cambridge, 1948.

[5] Bar-Cohen, Y., Biomimetics: Biologically Inspired Technologies, Taylor \& Francis Group, LLC: Boca Raton, FL, 2006.

[6] Gray, C.H., An interview with Jack E. Steele. The Cyborg Handbook, Routledge: New York \& London, pp. 61-69, 1995. doi: http://dx.doi.org/10.1177/110330889800600204

[7] Wahl, D.C., Bionics vs. biomimicry: from control of nature to sustainable participation in nature. Design and Nature III: Comparing Design in Nature With Science and Engineering, Vol. 87, ed. C.A. Brebbia, WIT Press: Ashurst, UK, 2006. doi: http://dx.doi.org/10.2495/ dn060281

[8] Nachtigall, W., Vorbild Natur: Bionik-Design für Funktionelles Gestalten, Springer Verlag: Berlin, 1997. doi: http://dx.doi.org/10.1007/978-3-642-60866-7 1

[9] Patterson, R., Otto Schmitt's contributions to basic and applied biomedical engineering and to the profession, Conference Proceedings: Annual International Conference of the IEEE Engineering in Medicine and Biology Society, 2009. doi: http://dx.doi.org/10.1109/ iembs.2009.5334039

[10] Schmitt, O.H., Cathode ray oscillograph for the investigation of nerve action potentials, Journal of Scientific Instruments, Nov. 1938. http://www.ece.umn.edu/users/schmitt/publicat/ patnpub.html

[11] Vincent, J.F.V., Bogatyreva, O.A., Bogatyrev, N.R., Bowyer, A. \& Pahl, A.-K., Biomimetics: its practice and theory. Journal of the Royal Society Interface, 3(9), pp. 471-482, 2006. doi: http://dx.doi.org/10.1098/rsif.2006.0127

[12] Vincent, J.F.V., Biomimetics - a review, Proceedings of the Institution of Mechanical Engineers, Part H: Journal of Engineering in Medicine, 223(8), pp. 919-939, 2009. doi: http:// dx.doi.org/10.1243/09544119jeim561

[13] Bar-Cohen, Y., Biomimetics - using nature to inspire human innovation. Bioinspiration and Biomimetics, 1(1), pp. 1-12, 2006. doi: http://dx.doi.org/10.1088/1748-3182/1/1/p01

[14] Harkness, J.M., A lifetime of connections - Otto Herbert Schmitt, 1913-1998. Phys. Perspect, 4(4), 456-490, 2001. doi: http://dx.doi.org/10.1007/s000160200005

[15] Jantsch, E., The Self-Organizing Universe: Scientific and Human Implications of the Emerging Paradigm of Evolution, Pergamon Press: New York, 1980.

[16] Laszlo, E., The Systems View of the World: The Natural Philosophy of New Developments in the Sciences, George Braziller: New York, 1972. doi: http://dx.doi.org/10.1017/ $\underline{\mathrm{s} 0012217300030377}$

[17] Capra, F., Ecology and Community [Online], available at www.ecoliteracy.org/essays/ecology-and-community, 2010.

[18] Miller, J.G., Living Systems, McGraw Hill: New York, 1978. doi: http://dx.doi.org/10.1002/ bs.3830250105 
[19] Bejan, A., Advanced Engineering Thermodynamics, 2nd edn, Wiley: New York, 1997. doi: http://dx.doi.org/10.1080/03043799808928263

[20] Bejan, A. \& Lorente, S., Constructal law of design and evolution: physics, biology, technology, and society. Journal of Applied Physics, 113(151301), 2013. doi: http://dx.doi. org/10.1063/1.4798429

[21] Todd, J. \& Todd, N.J., From Eco-Cities to Living Machines: Principles of Ecological Design, North Atlantic Books: Berkeley, 1993.

[22] Geselowitz, D.B., In Memoriam: Otto H. Schmitt. Annals of Biomedical Engineering, 26(5), pp. 739-740, 1998. doi: http://dx.doi.org/10.1114/1.127

[23] Todd, N.J. \& Todd, J., Bioshelters, Ocean Arks, City Farming, Sierra Club Books: San Francisco, 1984.

[24] DeKay, M., Integral Sustainable Design: Transformative Perspectives, Earthscan: London and Washington, DC, 2011. doi: http://dx.doi.org/10.4324/9781849775366

[25] The Biomimicry Institute, Innovation inspired by nature: biomimicry and design, Biomimicry Resource Handbook: A Seed Bank of Knowledge and Best Practices, The Biomimicry Institute: Missoula, 2010. doi: http://dx.doi.org/10.1016/b978-0-12-415995-2.00019-2

[26] National Academy of Sciences, A New Biology for the 21st Century, National Academy of Sciences: Washington, DC, 2009. doi: http://dx.doi.org/10.2172/6162073

[27] Müller, A., A brief history of the BCL: Heinz von Foerster and the Biological Computer Laboratory. An Unfinished Revolution? Heinz von Foerster and the Biological Computer Laboratory (BCL), 1958-1976, eds. A. Müller, K. Müller, Edition Echoraum: Vienna, pp. 279-302, 2007. doi: http://dx.doi.org/10.1108/03684920810877016

[28] Christian, D., Wahl, Daniel. Design Inspired by Nature: Survey on Terminology, Online survey 19 Feb 2012. 